\title{
Original THE USE OF STEREOTACTIC RADIOSURGERY AND RADIATION THERAPY Article IN THE MANAGEMENT OF ACOUSTIC NEUROMAS (NEMROCK EXPERIENCE 1999-2007)

\author{
Mohamed Abdulla ${ }^{1}$ and Mohamed Galal ${ }^{2}$
} \\ ${ }^{1}$ Clinical Oncology and Nuclear Medicine, Faculty of Medicine, Cairo University. ${ }^{2}$ Radiation Physics Unit, Kasr El-Aini Center of Clinical Oncology (NEMROCK), Cairo University.
}

\begin{abstract}
Introduction: Radiosurgery is presently a well established alternative to microsurgical resection of acoustic neuroma and many patients prefer radiosurgery because of the lower morbidity of the procedure with similar rates of local tumor control. The current study was conducted in Kasr El-Aini Department of Clinical Oncology and Nuclear Medicine (NEMROCK), Faculty of Medicine, Cairo University to assess the effectiveness and safety profiles in patients with acoustic neuroma treated by stereotactic radiosurgery and radiotherapy facility.

Patients and Methods: Between October 1999 and December 2007, 64 patients with acoustic neuroma were treated via Linac Based stereotactic radiosurgery and radiotherapy.

Results: The median age of treated patients was 45.5 years (+/- 12.8) with equal distribution among both genders. Unilateral disease was reported in 51 patients (79.7\%) with a median treatment volume of $11.6 \mathrm{~mm}^{3}(+/-13.2)$. The median dose received was 17.1 Gy (+/-3.98) via single fraction (SRS) in 43 patients and multiple fractions (FSRT) in 21 patients. After a median follow up of 38.3 months (+/-17.2); the majority of patients (75\%) had shown disease stability while $7.8 \%$ and $17.2 \%$ experienced increased and decreased lesion volumes with an overall response rate of $92.2 \%$. Moreover, $62.5 \%$ and $75 \%$ of patients had stable Gardner Robertson Scale and House-Brackmann Grade as compared to pre-treatment sitting.

Conclusion: Stereotactic radiosurgery and radiotherapy are effective procedures in treatment of acoustic neuroma with an accepted co-morbidity profile
\end{abstract}

Key Words: Stereotactic, radiosurgery, radiation therapy, acoustic neuroma.

Corresponding Author: Mohamed Abdulla, E-mail: Mohamedabdulla2001@yahoo.com

\section{INTRODUCTION}

Acoustic Neuromas are benign intracranial extraaxial tumors that arise from Shwann cells surrounding the vestibular nerves. They represent $8 \%$ of all intracranial tumors and have an overall incidence of 1:100000 personyears. These tumors can result in diminished hearing, facial numbness or weakness and balance disturbances. The management of acoustic Neuromas has changed during the past 30 years ${ }^{1}$.

Surgery was initially the mainstay of treatment and recent published data have shown local control rates as great as $97 \%$; however, even to the present, an unavoidable incidence of postoperative morbidity has remained, such as a loss of serviceable hearing, facial neuropathy and cerebrospinal fluid leak ${ }^{2}$. Stereotactic Radiosurgery (SRS) became an important non-invasive treatment alternative to surgical resection of acoustic Neuromas. A growing body of published data supports the use of single fraction (SRS) as the standard of care. As the median age at diagnosis of this disease is 50 years, comorbidities from treatment play an important role in the patient's quality of life. As such, although initial SRS has maintained local control with a low incidence of recurrence, the toxicity profile was again high with doses of 18-25 Gy. This led to a dose reduction to the common standard of 12 Gy, which reduced treatment morbidity while maximizing tumor control ${ }^{3}$.

More recent data have revealed that fractionated stereotactic radiotherapy (FSRT) may provide a comparably high rate of tumor control while also achieving a great rate of hearing preservation in the serviceable range ${ }^{4}$.

\section{PATIENTS AND METHODS}

Between October 1999 and December 2007, 64 patients with radiologically proven symptomatic acoustic neuromas presented to Kasr El-Aini Center of Oncology and Nuclear Medicine (NEMROCK), Kasr El-Aini School of Medicine, Cairo University; were treated via Linac-based stereotactic radiosurgery and radiation therapy facility. At presentation, all patients had a lower age limit of 18 years with progressive symptoms (Headache, Tinnitus, Hearing Defects, Facial Affection, etc). All lesions judged to be treated should have a maximum diameter of $\leq 50 \mathrm{~mm}$. 
Upon presentation, all patients were subjected to full evaluation by a board including the following specialities; radiation oncology, neurosurgery and ear, nose and throat diseases. Pre-treatment investigations included; Magnetic Resonance Imaging (MRI) with contrast (1 day before scheduled treatment), audiogram and conventional laboratory tests. The obtained Magnetic Resonance Images were transferred to the planning system (BrainScan ${ }^{\circledR}$ versions 4.3 , which was upgraded later to 5.31). The planned dose to be received was 10-20 Gy (SRS) or 500 cGy for 2-3 sessions (SRT)

\section{TREATMENT STEPS}

1. Fixation: through application of the head ring (for patients treated on single fraction radiosurgery basis) or the mask system (for those treated by fractionated stereotactic radiation therapy and patients refusing head ring application although treated by radiosurgery).

2. Localizer application.

3. $2 \mathrm{~mm}$ slice thickness CT-Scan with contrast administration.

4. Transfer of CT-Scan images to the planning system via cable network or Magnetic Optical Disk (MOD), (Fig. 1).

5. Setting the localizer points; (Fig. 2).

6. Delineation of the lesion (Target Volume) as well as the organs at risk (OAR) namely; both eyes, optic nerves and chiasm, brain stem and cervical cord and basilar artery in all cuts of MRI (Axial, coronal and Saggital) and CT, (Fig. 3).

7. Fusion of delineated structures in both sets of images. Initially fusion was attempted manually through pairing of objects till the year 2001, then

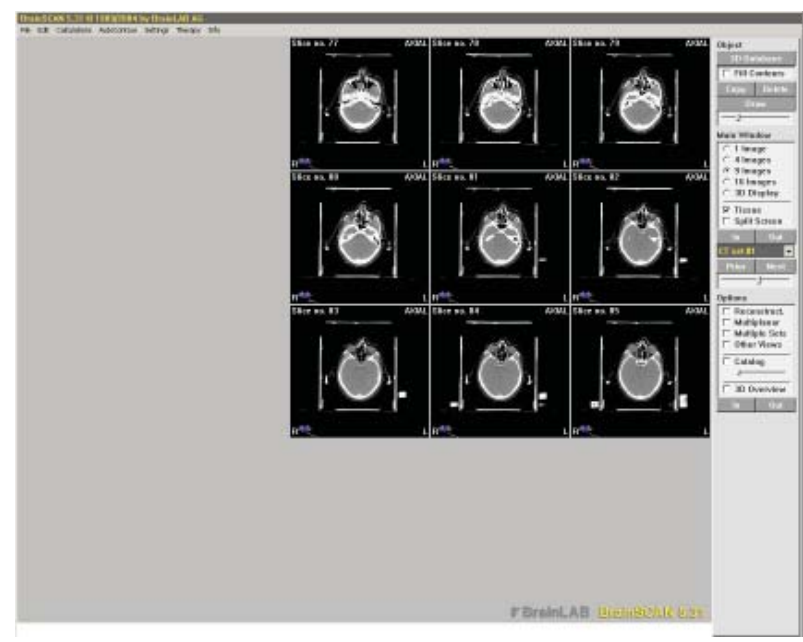

Fig. 1: CT-Scan After Transfer to Planning System automatically thereafter. Checking the paired structures in CT and MRI images to ensure their matching was a mandatory step, (Fig. 4).

8. Reconstruction of images in 3-dimension, (Fig.5).

9. Placement of treatment isocenters required according to lesion volume and shape (offered by the planning system; Smart Plan) and can be repositioned manually. Typically 1-3 isocenters were required (1-2 in most of cases), (Fig. 6).

10. Checking for dose wash throughout the different cuts to ensure covering of the target volume periphery within at least $90 \%$ isodose line in different angels of the arc movement, (Fig. 7).

11. Checking the radiation dose contribution to organs at risk (OAR) from used isocenters through different treatment arcs. Manual replacement of isocenters with changes in cone size as well arc movements in the form of shortening, lengthening or splitting were allowed to decrease radiation doses to organs at risk as lowest as possible, (Fig. 8).

12. Evaluation of cumulative and differential dose volume histograms and registration of conformality index; ideally it should be one with minor fractions, (Fig. 9).

13. Plan Acceptance.

14. Printing of treatment parameters; paper documentation and transparencies for isocenters application in relation to localizer grids for quality assurance and treatment.

15. Quality assurance was a mandatory step just before every treatment session for every single patient.

16. Treatment delivery.

17. Removal of the head ring or mask system.

18. Checking the patient's vital signs.

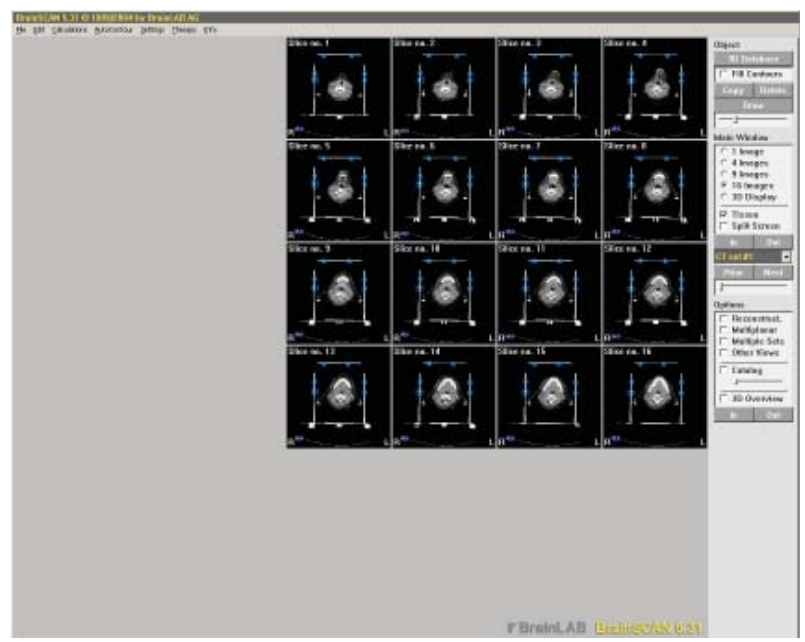

Fig. 2: Setting The Localizer Points. 


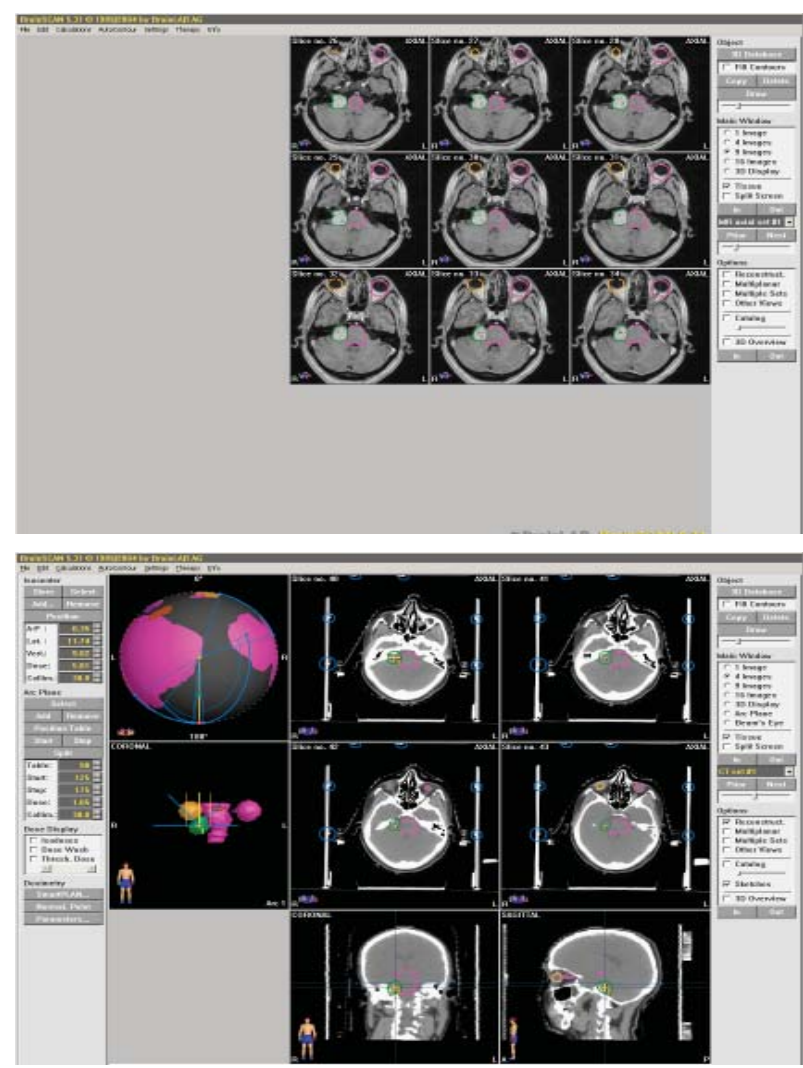

Fig. 3: Delineation of The Target Structures as well as Organs At Risk (OAR) in All MRI and CT Cuts.

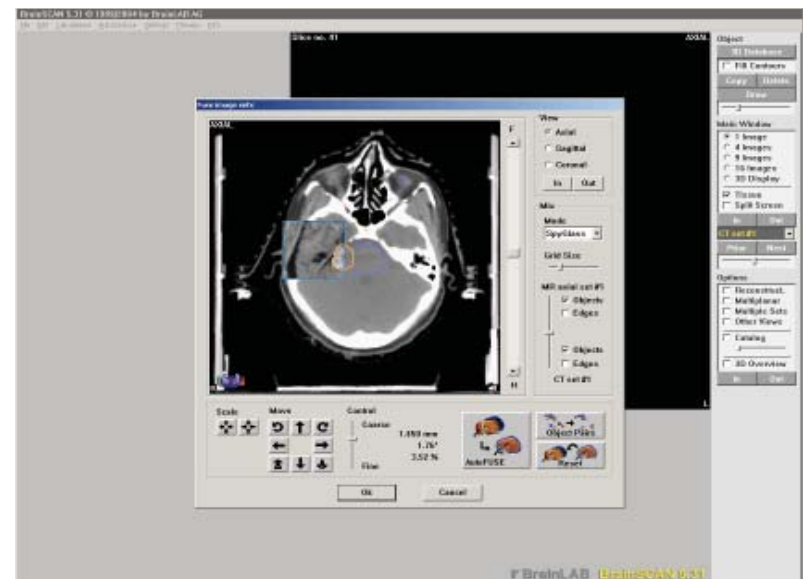

Fig. 4: Fusion of The CT \& MRI Delineated Cuts and Checking it Matching.

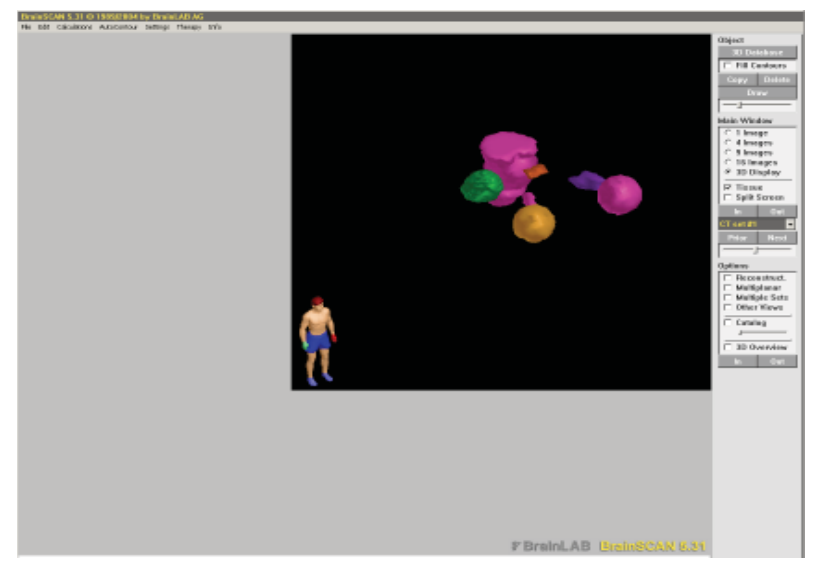

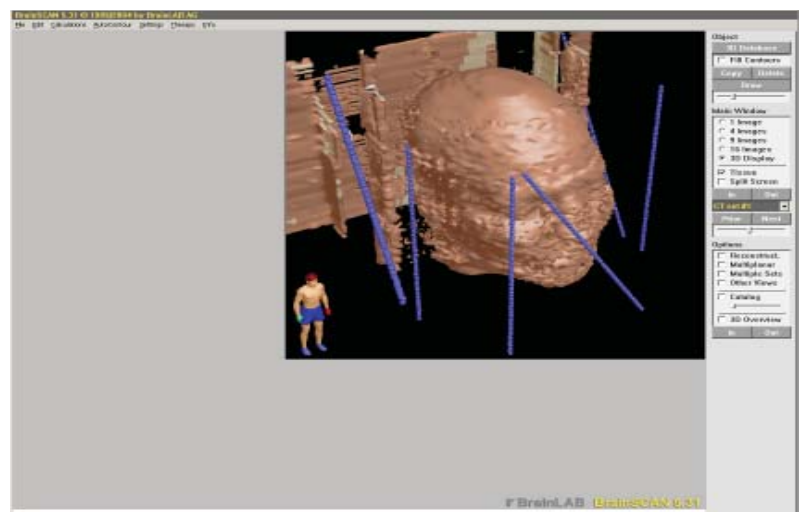

Fig. 5: Reconstruction of 3-Dimensional Image of the Target Structure and Organs at Risk.

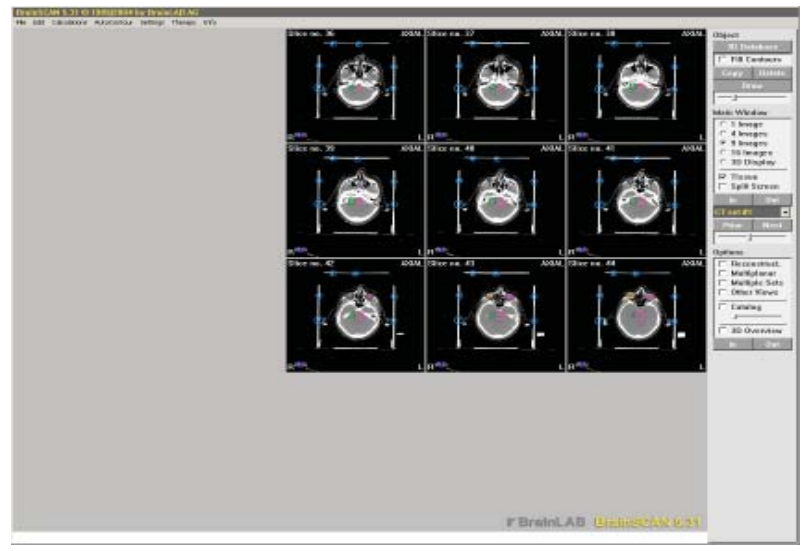

Fig. 6: Placement of Treatment Isocenters.
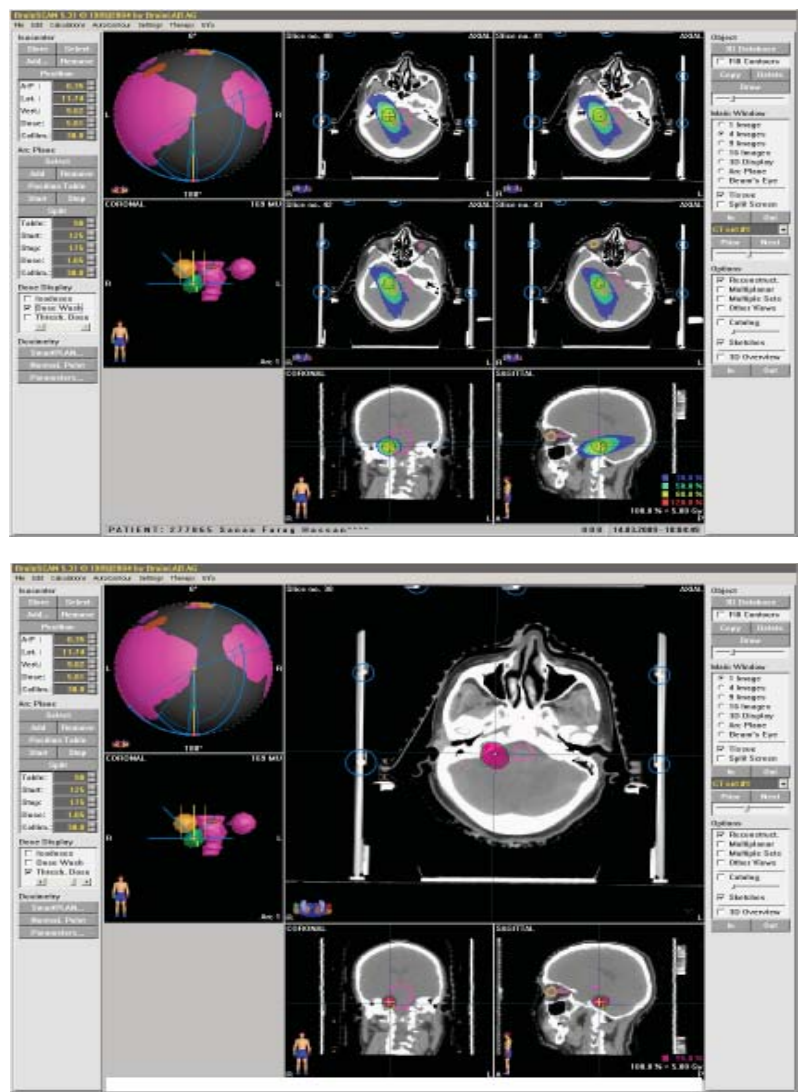

Fig. 7: Checking The Dose Wash Throughout The Different Cuts in Relation to Target and Risk Structures Ensuring Covering the Lesion within $90 \%$ Isodose. 


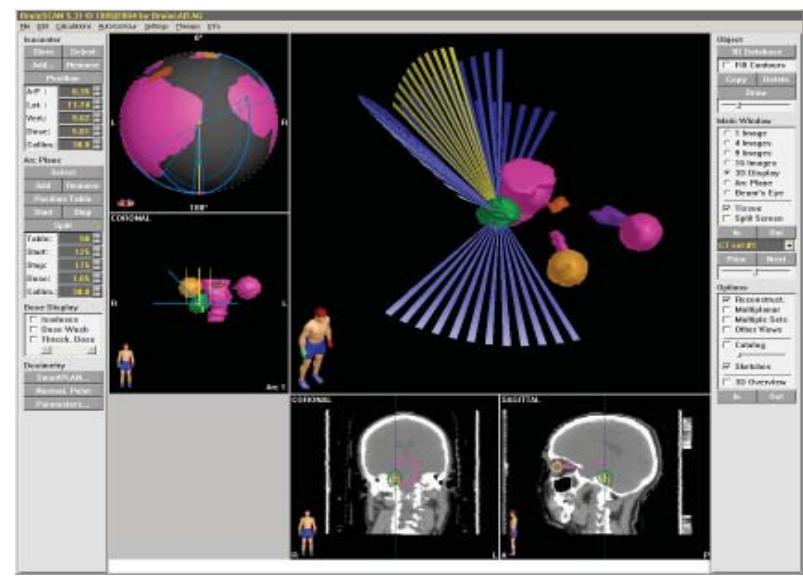

Fig. 8: Checking and Manual Adjustment of Isocenter, Cone Size, as well as Arc Angles to Optimize Dose Delivery to Target while as low as Possible Dose Contribution to Risk Structures..
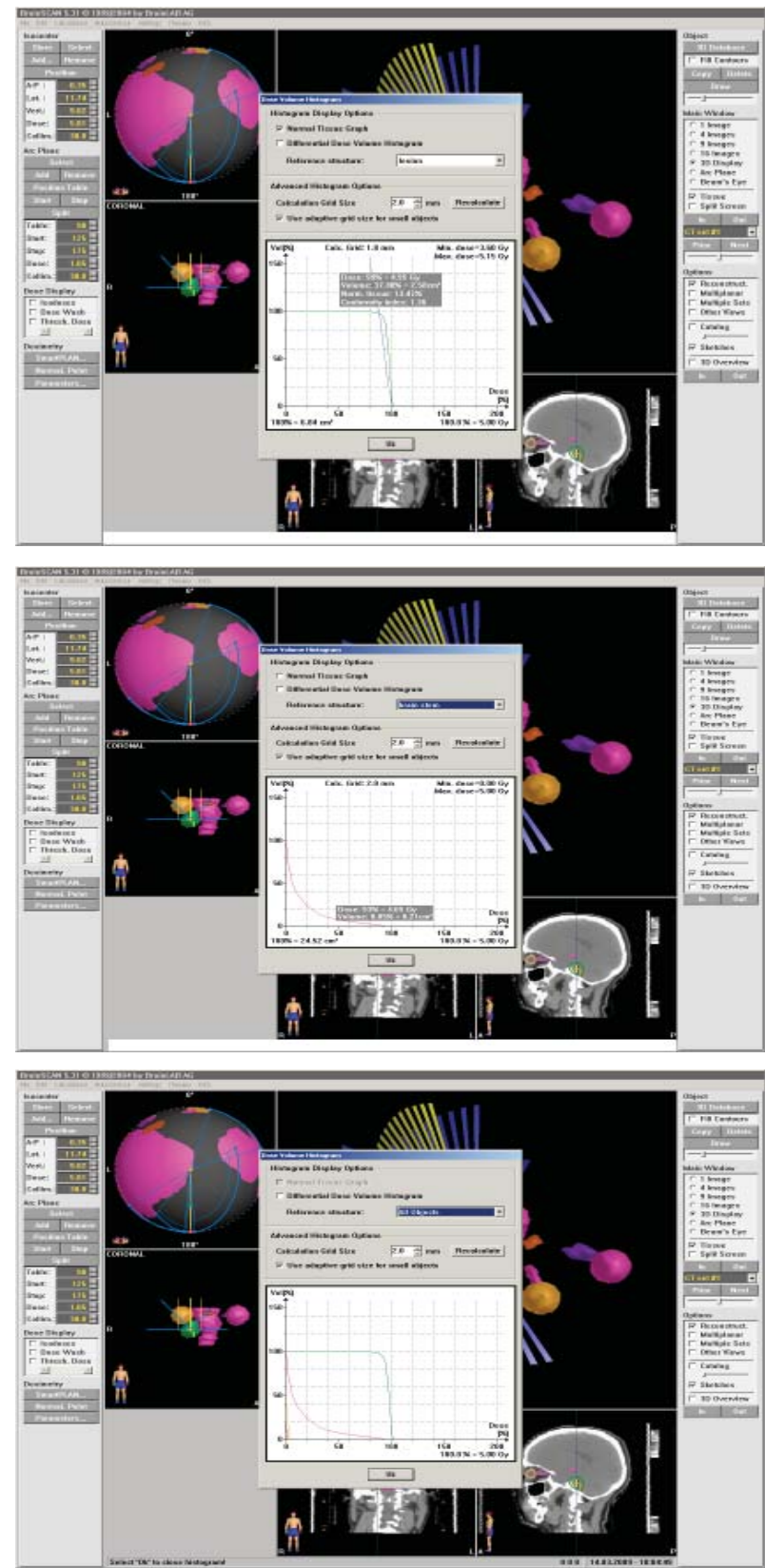

Fig. 9: Checking Dose Volume Histograms (DVH) and Conformality Index.

\section{Patient's Care:}

All patients were premedicated with anti-emetics, antacids, as well as steroids which were maintained and gradually tapered over two weeks post-treatment. Sedatives, analgesics and local anaesthetics at sites of the 4-bin application for head ring were considered to minimize patient's agony and pain.

\section{Patient's Follow up:}

All patients were followed up clinically for pretreatment as well as newly developed manifestations. Follow up MRI imaging were obtained every 6 months then repeated annually. Audiograms were repeated 6 months after treatment. For clinical assessment of hearing affection; the Gardner Robertson method ${ }^{5}$, while for evaluation of Facial Nerve affection; House-Brackmann Grading system ${ }^{6}$ were adopted, Tables (1) and (2).

Table 1: Gardner Robertson Classification of Hearing:

\begin{tabular}{cc}
\hline Class & Speech Discrimination Score \% \\
\hline 1 & $70-100$ \\
2 & $50-69$ \\
3 & $5-49$ \\
4 & $1-4$ \\
5 & 0 \\
\hline
\end{tabular}

Table 2: House-Brackmann Scale for Assessment of Facial Nerve Function.

\begin{tabular}{|c|c|c|}
\hline Grade & Function & Gross \\
\hline I & $\begin{array}{l}\text { Normal } \\
\text { facial } \\
\text { function. }\end{array}$ & Normal \\
\hline II & $\begin{array}{l}\text { Mild } \\
\text { Dysfunction. }\end{array}$ & $\begin{array}{l}\text { - Slight weakness noticeable } \\
\text { on close inspection. } \\
\text { - } \quad \text { May have slight synkinesis. } \\
\text { - } \quad \text { At rest, normal symmetry } \\
\text { and tone. }\end{array}$ \\
\hline III & $\begin{array}{l}\text { Moderate } \\
\text { Dysfunction. }\end{array}$ & $\begin{array}{l}\text { Obvious but not disfiguring } \\
\text { difference between the two sides. } \\
\text { Noticeable but not severe } \\
\text { synkinesis, contracture, or hemifacial } \\
\text { spasm. } \quad \text { At rest, normal symmetry } \\
\text { and tone. }\end{array}$ \\
\hline IV & $\begin{array}{l}\text { Moderately } \\
\text { Severe } \\
\text { Dysfunction. }\end{array}$ & $\begin{array}{l}\text { - Obvious weakness and/or } \\
\text { disfiguring asymmetry. } \\
\text { At rest, normal symmetry } \\
\text { and tone. }\end{array}$ \\
\hline V & $\begin{array}{l}\text { Severe } \\
\text { Dysfunction. }\end{array}$ & $\begin{array}{ll}\text { • } & \text { Only barely perceptible } \\
\text { motion. } & \\
\text { • } & \text { At rest, asymmetry. }\end{array}$ \\
\hline VI & $\begin{array}{l}\text { Total } \\
\text { Paralysis. }\end{array}$ & No Movement. \\
\hline
\end{tabular}

\section{RESULTS}

The current study had included 64 patients with radiologically proven acoustic neuromas presented to and treated in Kasr El-Aini Oncology Center (NEMROCK), Kasr El-Aini School of Medicine, Cairo University between October, 1999 through December 2007. Patient's 
characteristics are illustrated in Table (3). The male to female ratio was 1:1 (32 patients for each gender). The majority of patients were in the $5^{\text {th }}$ decade of life (34.4\%) while only $9.4 \%$ (6 patients) were in the $7^{\text {th }}$ decade of life with age range of 21-70 years and median age of 45.5 years (SD +/- 12.8 years). Among treated patients; 51 $(79.7 \%)$ had unilateral disease at presentation whereas 13 patients (20.3\%) had bilateral disease. Among 77 treated lesions; the diameter ranged from 8-47 mm with median value of $20 \mathrm{~mm}$ (SD +/- $9.45 \mathrm{~mm}$ ). The treated volumes ranged from $0.7 \mathrm{~mm}^{3}$ to $50.3 \mathrm{~mm}^{3}$ with a median value of $11.6 \mathrm{~mm}^{3}$ (SD +/- $13.2 \mathrm{~mm}^{3}$ ). The majority of patients upon presentation had symptoms of tinnitus (58 patients; 90.6\%), diminished hearing (24 patients; 37.5\%) and headache (42 patients; 65.6\%) for variable periods of time. Objective evaluation of hearing indicated that the majority of patients had serviceable hearing (Gardner Robertson Class 1,2 and 3) in 42 patients (65.6\%), while major facial affection was encountered in 3 patients (8.8\%) according to House Brackmann grading system.

Table 3: Patients’ Characteristics.

\begin{tabular}{|c|c|c|c|}
\hline \multirow{2}{*}{\multicolumn{2}{|c|}{ Item }} & \multicolumn{2}{|c|}{ Description } \\
\hline & & Number & $\%$ \\
\hline \multicolumn{4}{|c|}{ Age (Years): } \\
\hline$\bullet$ & $21-30$ & 13 & 20.3 \\
\hline - & $31-40$ & 13 & 20.3 \\
\hline$\bullet$ & $41-50$ & 22 & 34.4 \\
\hline - & $51-60$ & 10 & 15.6 \\
\hline$\bullet$ & $61-70$ & 6 & 9.4 \\
\hline \multicolumn{2}{|c|}{ Age Range } & \multicolumn{2}{|c|}{21 - 70 Years } \\
\hline Media Ag & & \multicolumn{2}{|c|}{45.5 (SD +/- 12.8 Years) } \\
\hline \multicolumn{4}{|l|}{ Gender: } \\
\hline$\bullet$ & Male & 32 & 50 \\
\hline - & Female & 32 & 50 \\
\hline \multicolumn{4}{|c|}{ Bilaterality: } \\
\hline \multirow{2}{*}{ - } & \multirow{2}{*}{ Bilateral } & 51 & 79.7 \\
\hline & & 13 & 20.3 \\
\hline \multicolumn{4}{|c|}{ Lesion Measurements: } \\
\hline$\bullet$ & Diameter: & & \\
\hline Range: & & \multicolumn{2}{|l|}{$8-47 \mathrm{~mm}$} \\
\hline Median: & Volume: & \multicolumn{2}{|c|}{$20(\mathrm{SD}+/-9.45 \mathrm{~mm})$} \\
\hline Range: & & \multirow{2}{*}{\multicolumn{2}{|c|}{$\begin{array}{l}0.7-50.3 \mathrm{~mm}^{3} \\
11.6\left(\mathrm{SD}+/-13.2 \mathrm{~mm}^{3}\right)\end{array}$}} \\
\hline Median: & & & \\
\hline \multicolumn{4}{|c|}{ Presenting Symptoms: } \\
\hline • & Tinnitus: & 58 & 90.6 \\
\hline$\bullet$ & Diminished Hearing: & 24 & 37.5 \\
\hline$\bullet$ & Headache: & 42 & 65.6 \\
\hline \multicolumn{4}{|c|}{ Hearing Assessment*: } \\
\hline$\bullet$ & GR Class 1, 2 and 3 & 42 & 65.6 \\
\hline$\bullet$ & GR Class 4 and 5 & 22 & 34.4 \\
\hline \multicolumn{4}{|c|}{ Facial Assessment**: } \\
\hline$\bullet$ & Major Affection: & 3 & 8.8 \\
\hline$\bullet$ & Minor Affection: & 61 & 91.2 \\
\hline
\end{tabular}

GR: Gardner Robertson Classification of Hearing.Facial Assessment According to House-Brackmann Scaling System

Regarding the fixation method and treatment technique; head ring was applied in 38 patients (59.4\%) whereas mask system fixation was adopted in 26 patients (40.6\%). Single Fraction Treatment (Stereotactic
Radiosurgery) was adopted in all 38 patients fixed via the head ring, while 21 out of 26 patients fixed via the mask system (33\% of the entire group) had received fractionated stereotactic radiation therapy (5 Gy/fraction for 2-3 sessions, every other day) according to lesion size and radiation exposure to nearby organs at risk (OAR). The total dose received ranged from $10-20$ Gy with a median value of $17.1 \mathrm{~Gy}$ (SD +/- $3.98 \mathrm{~Gy}$ ). Among 77 treated lesions; two isocenters were required to homogenously cover the treatment volume in 39 (50.7\%) lesions, while one and three isocenters were used in $28(36.4 \%)$ and 10 (12.9\%) lesions respectively. The treatment related parameters are illustrated in (Table 4).

Table 4: Treatment Related Parameters

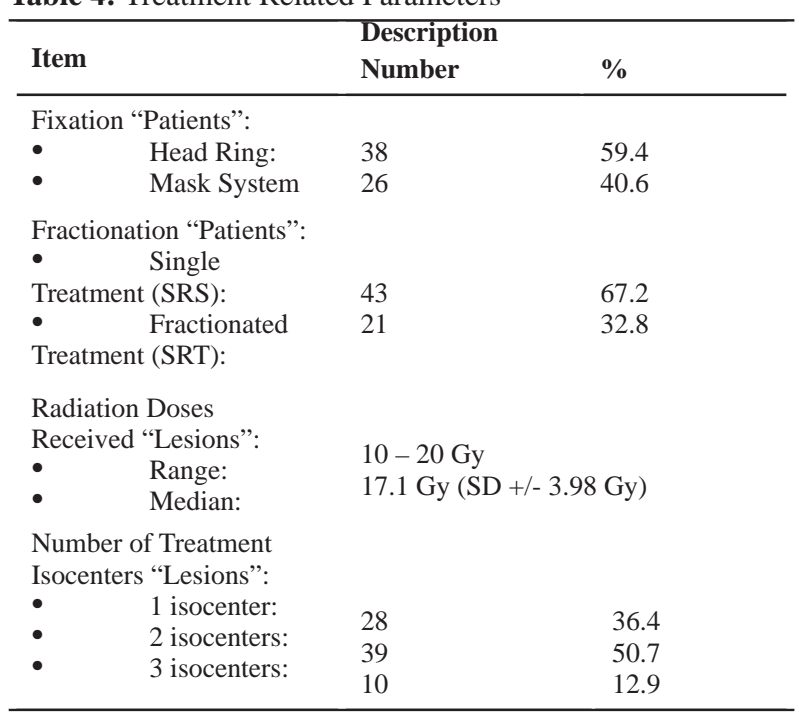

The follow up period had ranged from $15-60$ months with a median follow up period of 38.3 months (SD +/- 17.2 months). Magnetic Resonance Imaging (MRI) with Gadolinium administration after 6 months revealed regressive lesions in 2 patients (3.1\%) and progressive course in 3 patients (4.7\%), while serial follow up images thereafter revealed an additional 3 (4.7\%) and 8 (12.5\%) patients with regressive as well as progressive course of disease respectively. The remaining 48 (75\%) had showns Table disease throughout the follow up period with variable grades of degeneration within lesions as shown in (Table 5).

Table 5: Radiological Response Among Treated Patients:

\begin{tabular}{|c|c|c|c|c|c|c|}
\hline \multirow{3}{*}{$\begin{array}{l}\text { Radiological } \\
\text { Response }\end{array}$} & \multicolumn{4}{|c|}{ Onset of Response } & \multirow{2}{*}{\multicolumn{2}{|c|}{ Total }} \\
\hline & \multicolumn{2}{|c|}{$<6$ months } & \multicolumn{2}{|c|}{$>6$ months } & & \\
\hline & Number & $\%$ & Number & $\%$ & Number & $\%$ \\
\hline $\begin{array}{l}\text { Increased } \\
\text { Size }\end{array}$ & 2 & 3.1 & 3 & 4.7 & 5 & 7.8 \\
\hline $\begin{array}{l}\text { Decreased } \\
\text { Size }\end{array}$ & 3 & 4.7 & 8 & 12.5 & 11 & 17.2 \\
\hline Stable & \multicolumn{4}{|c|}{48 (75\%) } & 48 & 75 \\
\hline
\end{tabular}


Among treated patients, 62.5\% (40 patients) had shown stability of pre-treatment speech discrimination ability (i.e.stable Gardner Robertson Scale), whereas, deterioration was documented in 24 patients (37.5\%). Moreover, 16 patients (25\%) had experienced deterioration in the facial nerve function according to House Brackmann grading system, whereas, 48 patients (75\%) remained unaffected as shown in (Tables 6 and7).

Table 6: Treatment Impact upon Hearing Affection According to Gardner Robertson Scale.

\begin{tabular}{|c|c|c|}
\hline Gardner $\quad$ Robertson & Number & $\%$ \\
\hline \multicolumn{3}{|l|}{ Scale } \\
\hline Stable & 40 & 62.5 \\
\hline Deteriorated & 24 & 37.5 \\
\hline Total & 64 & 100 \\
\hline
\end{tabular}

Table 7: Treatment Impact upon Facial Nerve Affection According to House-Brackmann Grading System.

\begin{tabular}{ccc}
\hline $\begin{array}{c}\text { House-Brackmann Grading } \\
\text { System }\end{array}$ & Number & $\%$ \\
\hline Stable & 48 & $75 \%$ \\
Deteriorated & 16 & $25 \%$ \\
Total & 64 & 100 \\
\hline DISCUSSION & & \\
\hline
\end{tabular}

Radiosurgery is presently a well established alternative to microsurgical resection of acoustic neuroma. Many patients prefer radiosurgery over resection because of lower morbidity of the procedure and similar rates of long term tumor control. However, radiosurgery was reported to be associated with significant morbidity in the form of facial weakness and numbness as well as decreased hearing in 21, 27 and 49\% of treated patients with radiation doses in excess of or more $16 \mathrm{~Gy}^{7-9}$. When comparing microsurgical treatment of AN tumors to radiation therapy, it is important to keep in mind the different goals of these therapeutic modalities. The goal of microsurgery is to resect the tumor and leave little or no disease behind. Radiation therapy, however, aims to arrest the growth of the tumor or cause it to become smaller. In all the studies reviewed, successful control was defined as no enlargement of the tumor on serial MRI scans. Success of surgical treatment cannot necessarily be equated with the success of RS or FSRT ${ }^{10}$.

In the current age, the median age was reported to be 45.5 (SD +/- 12.8) years, with equal distribution among both genders. The presenting manifestations were tinnitus, headache and diminished hearing in $90.6 \%, 37.5 \%$ and $65.6 \%$ respectively. Objectively; the diminished serviceable hearing (Gardner Robertson Classes 4 and 5) was documented in 22 patients (34.4\%), while major facial affection was reported in only 3 patients (8.8\%) going in agreement with most of the reported literatures except for the slight male predominance (Male : Female $=1.1: 1)^{3}$. Bilateral disease was encountered among13 patients (20.3\%), non of them reported to have generalized neurofibromatosis in contrast to the reported international fig. ranging from 3.6 - 5.4\% mostly encountered in patients with neurofibromatosis type $2^{11}$, a finding that can be attributed to the relatively small number of patients included in our study.

In our study, the diameter of treated lesions had ranged from $8-47 \mathrm{~mm}$ (median diameter $=20+/-9.45$ $\mathrm{mm}$ ) with a calculated volume range of $0.7-50.3 \mathrm{~mm}^{3}$ (median volume $=11.6+/-13.2 \mathrm{~mm}^{3}$ ). Many authors ${ }^{4}$ had reported a wide range of measurements for lesions indicated to be treated by stereotactic radiosurgery and radiation therapy with a diameter ranging from less than $1.0 \mathrm{~mm}$ and up to $55 \mathrm{~mm}$ as well as volume ranges of $0.4-50 \mathrm{~mm}^{3}$, emphasizing the special importance of restricting such treatment technique to the smallest possible lesion volume with upper limit of $40-50$ mm longest diameter to guard against radiation dose contribution to the surrounding and nearby organs at risk (OAR) in such benign disease entity with comparable life span to general population of the same age group.

The experience of LINAC based stereotactic therapy at Cleveland Clinic Foundation was described by Suh and colleagues in the year $2000^{12}$, where they treated 29 patients with acoustic neuromas. The tumor volume ranged from $0.18-28.7 \mathrm{~mm}^{3}$ (median volume $=21$ $\mathrm{mm} 3)$. One and two isocenters were used in 24 (82.75\%) and $5(17.24 \%)$ patients to homogenously cover the lesions within $80 \%$ isodose line to a median dose of 16 Gy. Among our patients, the treatment data were similar regarding the median radiation dose received (17.1 Gy), however the frequency of using 2 and 3 isocenters was quite higher (50.7\% and $12.9 \%$, respectively) although a comparable median lesion volume $\left(11.6+/-13.2 \mathrm{~mm}^{3}\right)$ was recorded, a finding can be attributed to the use of circular cones in treatment technique of NEMROCK series, where treatment was primarily delivered via multi-leaf collimators in the other group. Moreover, after a median follow up of 49 months, they reported radiological no change in size in 17 patients (58.6\%) and a decreased volume in 11 patients (37.9\%) with an overall response rate of $(96.5 \%)$. A rather similar outcome was obtained in our series after a median follow up of 38.3 (+/- 17.2) months with disease stability reported in 48 patients (75\%), while increased and decreased volumes were documented in 5 (7.8\%) and 11 (17.2\%) patients with an overall response rate of $92.2 \%$ reflecting the effectiveness of the adopted therapeutic modality. Moreover, similar data about tumor control were obtained from meta-analysis of several trials addressing treatment with stereotactic radiosurgery (RS) and fractionated stereotactic radiation therapy treatment (FSRT). The tumor control following stereotactic radiosurgery had ranged from $73.8 \%$ to $100 \%$ and $91.4 \%$ 
to $100 \%$ following fractionated stereotactic radiation therapy ${ }^{10}$.

The location of acoustic neuroma tumors jeopardizes hearing. Many patients present with varying degrees of hearing loss, which unfortunately is not restored. In general, the best outcome after irradiation of an acoustic neuroma is to maintain the pre-treatment hearing level. Many authors had suggested that the probability rate of useful hearing preservation in patients treated with radiosurgery ranges from (47)71\% ${ }^{13-15}$, however, it is more favourable following fractionated stereotactic radiation therapy (57)100\% ${ }^{16}$. These data are going in accordance with hearing preservation figures among our patients; where 40 patients $(62.5 \%)$ had shown stability of the pre-treatment speech discrimination ability. On the other hand, 24 patients (37.5\%) experienced mild deterioration, reflecting the ability of stereotactic radiosurgery and radiation therapy to achieve adequate tumor control without significant alteration of the pretreatment hearing power.

Facial nerve dysfunction was reported to be encountered following stereotactic radiosurgery and radiotherapy for acoustic neuromas with variable incidence ( $0 \%$ - 54\%); a rather wide range that might be attributed to heterogeneity of treatment protocols and tumor sizes, however it is expected to be more pronounced with larger tumors ${ }^{17}$. A matched incidence was reported among our patients, where 16 patients (25\%) had experienced deteriorated House Brackmann scoring system. Further studies with patients stratification according to size, total dose received and single versus fractionated treatment schedule are required to establish a firm conclusion.

The uses of Linear Accelerator based stereotactic radiosurgery and radiotherapy are essentially safe procedures in the management of acoustic neuromas, however, they are associated with considerable risk of deterioration of pre-existing neurological deficits. Their use should be restricted to as small as possible lesions to minimize radiation dose contribution to nearby organs at risk. Moreover, future studies directly comparing the single versus fractionated treatment schedule should be encouraged to establish a final conclusion about the superiority of either schedule to achieve better tumor control with lower toxicity profiles.

\section{REFERENCES}

1. Pollock BE, Driscoll CL, Foote RL, Link MJ, Gorman DA, Bauch CD, et al. Patient outcomes after vestibular schwannoma management: A prospective comparison of microsurgical resection and stereotactic radiosurgery. Neurosurgery 2006 Jul;59(1):77,85; discussion 77-85.
2. Karpinos M, Teh BS, Zeck O, Carpenter LS, Phan C, Mai WY, et al. Treatment of acoustic neuroma: Stereotactic radiosurgery vs. microsurgery. Int.J.Radiat.Oncol.Biol.Phys. 2002 Dec 1;54(5):1410-21.

3. Flickinger JC, Kondziolka D, Niranjan A, Maitz A, Voynov G, Lunsford LD. Acoustic neuroma radiosurgery with marginal tumor doses of 12 to 13 Gy. Int.J.Radiat.Oncol.Biol.Phys. 2004 Sep 1;60(1):225-30.

4. Combs SE, Volk S, Schulz Ertner D, Huber PE, Thilmann C, Debus J. Management of acoustic neuromas with fractionated stereotactic radiotherapy (FSRT): Long-term results in 106 patients treated in a single institution. Int.J.Radiat.Oncol.Biol. Phys. 2005 Sep 1;63(1):75-81.

5. Meyer TA, Canty PA, Wilkinson EP, Hansen MR, Rubinstein JT, Gantz BJ. Small acoustic neuromas: Surgical outcomes versus observation or radiation. Otol.Neurotol. 2006 Apr;27(3):380-92.

6. House JW, Brackmann DE. Facial nerve grading system. Otolaryngol.Head.Neck.Surg. 1985 Apr;93(2):146-7.

7. Kondziolka D, Lunsford LD, McLaughlin MR, Flickinger JC. Long-term outcomes after radiosurgery for acoustic neuromas. N.Engl.J.Med. 1998 Nov 12;339(20):1426-33.

8. Pollock BE, Lunsford LD, Kondziolka D, Flickinger JC, Bissonette DJ, Kelsey SF, et al. Outcome analysis of acoustic neuroma management: A comparison of microsurgery and stereotactic radiosurgery. Neurosurgery 1995 Jan;36(1):215,24; discussion 224-9.

9. Flickinger JC, Kondziolka D, Niranjan A, Lunsford LD. Results of acoustic neuroma radiosurgery: An analysis of 5 years' experience using current methods. J.Neurosurg. 2001 Jan;94(1):1-6.

10. Likhterov I, Allbright RM, Selesnick SH. LINAC radiosurgery and radiotherapy treatment of acoustic neuromas. Otolaryngol. Clin.North Am. 2007 Jun;40(3):541,70, ix.

11. Maire JP, Huchet A, Milbeo Y, Darrouzet V, Causse N, Celerier $D$, et al. Twenty years' experience in the treatment of acoustic neuromas with fractionated radiotherapy: A review of 45 cases. Int.J.Radiat.Oncol.Biol.Phys. 2006 Sep 1;66(1):170-8.

12. Suh JH, Barnett GH, Sohn JW, Kupelian PA, Cohen BH. Results of linear accelerator-based stereotactic radiosurgery for recurrent and newly diagnosed acoustic neuromas. Int.J.Cancer 2000 Jun 20;90(3):145-51.

13. Spiegelmann R, Lidar Z, Gofman J, Alezra D, Hadani M, Pfeffer R. Linear accelerator radiosurgery for vestibular schwannoma. J.Neurosurg. 2001 Jan;94(1):7-13.

14. Okunaga T, Matsuo T, Hayashi N, Hayashi Y, Shabani HK, Kaminogo M, et al. Linear accelerator radiosurgery for vestibular schwannoma: Measuring tumor volume changes on serial threedimensional spoiled gradient-echo magnetic resonance images. J.Neurosurg. 2005 Jul;103(1):53-8.

15. Roos DE, Brophy BP, Bhat MK, Katsilis ES. Update of radiosurgery at the Royal Adelaide Hospital. Australas.Radiol. 2006 Apr;50(2):158-67.

16. Williams JA. Fractionated stereotactic radiotherapy for acoustic neuromas. Int.J.Radiat.Oncol.Biol.Phys. 2002 Oct 1;54(2):500-4.

17. Chan AW, Black P, Ojemann RG, Barker FG,2nd, Kooy HM, Lopes $\mathrm{VV}$, et al. Stereotactic radiotherapy for vestibular schwannomas: Favorable outcome with minimal toxicity. Neurosurgery 2005 Jul;57(1):60,70; discussion 60-70. 